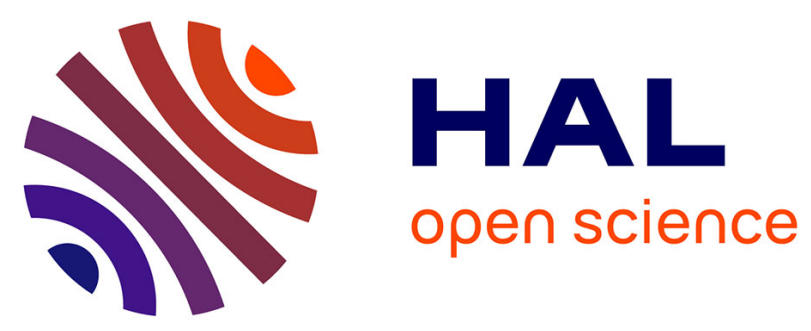

\title{
Tocolysis after preterm premature rupture of membranes and neonatal outcome: a propensity-score analysis
}

Elsa Lorthe, François Goffinet, Stéphane Marret, Christophe Vayssiere, Cyril Flamant, Mathilde Quere, Valérie Benhammou, Pierre-Yves Ancel, Gilles

Kayem

\section{To cite this version:}

Elsa Lorthe, François Goffinet, Stéphane Marret, Christophe Vayssiere, Cyril Flamant, et al.. Tocolysis after preterm premature rupture of membranes and neonatal outcome: a propensityscore analysis. American Journal of Obstetrics and Gynecology, 2017, 217 (2), pp.212.e1-212.e12. 10.1016/j.ajog.2017.04.015 . hal-01688552

\section{HAL Id: hal-01688552 https://hal.sorbonne-universite.fr/hal-01688552}

Submitted on 19 Jan 2018

HAL is a multi-disciplinary open access archive for the deposit and dissemination of scientific research documents, whether they are published or not. The documents may come from teaching and research institutions in France or abroad, or from public or private research centers.
L'archive ouverte pluridisciplinaire HAL, est destinée au dépôt et à la diffusion de documents scientifiques de niveau recherche, publiés ou non, émanant des établissements d'enseignement et de recherche français ou étrangers, des laboratoires publics ou privés. 
Tocolysis after preterm premature rupture of membranes and neonatal outcome: a propensity-score analysis

Elsa LORTHE ${ }^{1,2}$, RM, MSc, François GOFFINET ${ }^{1,3}$, MD, PhD, Stéphane MARRET ${ }^{4}$, MD, PhD, Christophe VAYSSIERE ${ }^{5,6}, \mathrm{MD}, \mathrm{PhD}$, Cyril FLAMANT ${ }^{7}, \mathrm{MD}, \mathrm{PhD}$, Mathilde QUERE $^{1}$, MSc, Valérie BENHAMMOU ${ }^{1}, \mathrm{PhD}$, Pierre-Yves ANCEL ${ }^{1,8}, \mathrm{MD}, \mathrm{PhD}$, Gilles KAYEM $^{1,2,9}$, MD, PhD

${ }^{1}$ Inserm UMR 1153, Obstetrical, Perinatal and Pediatric Epidemiology Research Team (Epopé), Center for Epidemiology and Statistics Sorbonne Paris Cité, Département HospitaloUniversitaire Risks in pregnancy, Paris Descartes University

${ }^{2}$ Sorbonne Universités, Université Pierre and Marie Curie Paris 06, Institut de Formation Doctorale, 4 Place Jussieu, 75252 PARIS cedex 05, Paris, France

${ }^{3}$ Department of Obstetrics and Gynecology, Cochin, Broca, Hôtel Dieu Hospital, Assistance Publique-Hôpitaux de Paris, Paris, France

${ }^{4}$ Department of Neonatal Medicine, Rouen University Hospital and Région-INSERM (ERI 28), Normandy University, Rouen, France

${ }^{5}$ Department of Obstetrics and Gynecology, University Hospital, Toulouse, France

${ }^{6}$ Research Unit on Perinatal Epidemiology, Childhood Disabilities and Adolescent Health, INSERM UMR 1027, Paul Sabatier University, Toulouse, France

${ }^{7}$ Department of Neonatal Medicine, Nantes University Hospital, Nantes, France

${ }^{8}$ Unité de Recherche Clinique - Centre d'Investigations Cliniques P1419, Département Hospitalo-Universitaire Risks in Pregnancy, Cochin Hotel-Dieu Hospital, APHP, Paris F75014, France

${ }^{9}$ Department of Obstetrics and Gynecology, Trousseau Hospital, APHP, Paris, France

Disclosure of interests: The authors report no conflict of interest.

\section{Funding sources:}

EPIPAGE 2 was funded by the French Institute of Public Health Research/Institute of Public Health and its partners: the French Health Ministry, the National Institute of Health and Medical Research (INSERM), the National Institute of Cancer, and the National Solidarity Fund for Autonomy (CNSA); the National Research Agency through the French EQUIPEX program of investments for the future (reference ANR-11-EQPX-0038); and the PREMUP Foundation. The funders had no role in the study design, data collection and analysis, decision to publish, or preparation of the manuscript.

Presentation information: These findings were presented at SMFM's 37th Annual Pregnancy Meeting, Las Vegas, NV, January 23-28, 2017.

Corresponding author: Ms Elsa Lorthe, INSERM U1153, Bâtiment Recherche, Hôpital Tenon, 4 rue de la Chine, 75020 Paris, France. Phone +33 1560183 67, fax +331 560171 88. Email: elsa.lorthe@gmail.com

Word count: Abstract: 361 words Text: 3100 words Table 3 is to appear in the print issue. 
51

52 53

54

55

56

57

58

59

60

61

62

63

64

65

66

67

68

69

70

71

72

73

74

75

76

77

53

Condensation: Although frequently administered, tocolysis after preterm premature rupture of membranes is not associated with improved neonatal outcome, prolonged gestation or increased rate of histological chorioamnionitis.

Short title: Tocolysis after PPROM and neonatal outcome

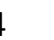

5

6

7

58

9

60

2

63

64

65

6

67

68

69

70




\section{Abstract}

Background: There are conflicting results regarding tocolysis in cases of preterm premature rupture of membranes. Delaying delivery may reduce neonatal morbidity due to prematurity, allow for prenatal corticosteroids and, if necessary, in utero transfer. However, that may increase risks of maternofetal infection and its adverse consequences.

Objective: To investigate whether tocolytic therapy in cases of preterm premature rupture of membranes is associated with improved neonatal or obstetric outcomes.

Study design: EPIPAGE 2 is a French national prospective population-based cohort study of preterm births that occurred in 546 maternity units in 2011. Inclusion criteria in this analysis were women with preterm premature rupture of membranes at 24 to 32 weeks' gestation and singleton gestations. Outcomes were survival to discharge without severe morbidity, latency prolonged by $\geq 48$ hours and histological chorioamnionitis. Uterine contractions at admission, individual and obstetric characteristics, and neonatal outcomes were compared by tocolytic treatment or not. Propensity scores and inverse probability of treatment weighting for each woman were used to minimize indication bias in estimating the association of tocolytic therapy with outcomes.

Results: The study population consisted of 803 women; 596 (73.4\%) received tocolysis. Women with and without tocolysis did not differ in neonatal survival without severe morbidity ( $86.7 \%$ vs $83.9 \%, \mathrm{p}=.39)$, latency prolonged by $\geq 48 \mathrm{hr}(75.1 \%$ vs $77.4 \%, \mathrm{p}=.59)$ or histological chorioamnionitis $(50.0 \%$ vs $47.6 \%, \mathrm{p}=.73)$. After applying propensity scores and assigning inverse probability of treatment weighting, tocolysis was not associated with improved survival without severe morbidity as compared with no tocolysis (odds ratio 1.01 [95\% Confidence Interval 0.94-1.09], latency prolonged by $\geq 48 \mathrm{hr}(1.03$ [0.95-1.11]), or histological chorioamnionitis (1.03 [0.92-1.17]). There was no association between the initial tocolytic drug used (oxytocin receptor antagonists or calcium-channel blockers vs no 
tocolysis) and the three outcomes. Sensitivity analyses of women (1) with preterm premature rupture of membranes at 26 to 31 weeks' gestation, (2) who delivered at least $12 \mathrm{hr}$ after rupture of membranes, with direct admission after the rupture of membranes and (3) presence or (4) absence of contractions, gave similar results.

Conclusion: Tocolysis in cases of preterm premature rupture of membranes is not associated with improved obstetric or neonatal outcomes; its clinical benefit remains un-proven.

Key words: EPIPAGE 2, preterm premature rupture of membranes, tocolysis, propensity score, survival, prematurity, severe morbidity, chorioamnionitis, latency.

(1) 


\section{Introduction}

Preterm premature rupture of membranes (PPROM) is responsible for one third of preterm births ${ }^{1}$ and represents a major cause of neonatal mortality and morbidity. ${ }^{1-3}$ Recommended clinical care before 34 weeks' gestation, in the absence of labor, chorioamnionitis or fetal distress, include antenatal steroids, antibiotics and expectant management to reduce prematurity and its adverse neonatal consequences. ${ }^{4-7}$

However, the use of tocolysis in cases of PPROM remains controversial. ${ }^{4,8}$ Indeed, delaying delivery may allow for prenatal corticosteroids and in utero transfer and reduce neonatal morbidity due to prematurity. But it may also prolong fetal exposure to maternofetal infection thereby increasing the risks of neonatal morbidity and mortality.

Only a few randomized controlled trials have addressed this issue, with different primary outcomes and conflicting results. ${ }^{9-18}$ These trials have small sample sizes, and most are old with obstetric interventions inconsistent with current practices, thus limiting the external validity and reliability of their findings. In some cases, the study design limited the inclusion of women with active contractions and therefore the applicability of the results to "real-life" practice. ${ }^{10,14,15,18}$ Even without strong evidence of its usefulness, ${ }^{5}$ tocolysis is widely prescribed to delay delivery and provide adequate prenatal care. ${ }^{19,20}$ In France, in the absence of clear recommendations, ${ }^{4}$ the use of tocolysis after PPROM varies according to the health center and its local policy. ${ }^{20}$

To investigate whether tocolysis administration was associated with improved neonatal and obstetric outcomes after PPROM, we performed a secondary analysis of a national population-based prospective cohort of preterm infants recruited in France in 2011. ${ }^{21}$

\section{Materials and Methods}

This a secondary analysis of EPIPAGE 2 (Etude épidémiologique sur les petits âges gestationnels 2), a prospective, national, population-based cohort study that was implemented 
153

154

155

156

157

158

159

160

161

162

163

164

165

166

167

168

169

170

171

172

173

174

175

176

177

to describe short- and long-term outcomes among preterm infants from birth to 12 years old as a function of their birth circumstances, including medical interventions and organization of care. $^{21}$

\section{Setting and data collection of the EPIPAGE 2 cohort study}

Briefly, eligible participants included all live births, stillbirths and terminations of pregnancy at $22^{0 / 7}$ to $34^{6 / 7}$ weeks' gestation from March to December 2011 in 25 French regions involving 546 maternity units, whose parents had not declined to participate. Infants were recruited during 3 different periods by gestational age at birth: 8-month recruitment for births at 22-26 completed weeks' gestation, 6-month recruitment for births at 27-31 weeks, and 5week recruitment for births at 32-34 weeks. Extremely preterm births (22-26 weeks) were recruited during a longer period because of their very low incidence and only a sample of moderate preterm births (32-34 weeks) was recruited. ${ }^{21}$ Maternal, obstetric, and neonatal data were collected following a standardized protocol. Full details of the cohort recruitment and data collection were previously reported elsewhere. ${ }^{21}$

\section{Ethics}

As required by French law and regulations, EPIPAGE 2 was approved by the national data protection authority (Comission Nationale de l'Informatique et des Libertés, CNIL $\mathrm{n}^{\circ}$ 911009), the appropriate ethics committees (CCTIRS: Comité Consultatif sur le Traitement de l'Information en matière de Recherche, approval granted November 18, 2010) and the committee for the protection of people participating in biomedical research (CPP: Comité de Protection des Personnes, approval granted March 18, 2011).

\section{Participants}

In the present study we included women with PPROM at 24 to 32 completed weeks' gestation, with a single fetus alive at the time of PPROM and born between 24 and 34 weeks. PPROM was defined as spontaneous rupture of membranes occurring before admission to a 
delivery room and diagnosed at least two hours before birth. As recommended, the diagnosis was based on maternal history and sterile speculum examination with a diagnostic test if necessary. ${ }^{4,5}$ Women with multiple pregnancies $(n=2020)$, terminations of pregnancy $(n=1292)$, homebirths $(n=54)$, fetal death before maternal admission at hospital $(n=675)$, lethal malformations $(n=103)$ and precursor to delivery other than PPROM ( $n=2220)$ were excluded. We also excluded infants with care limitations due to an antenatal diagnosis of poor prognosis $(n=8)$. Care limitations were defined as antenatal decisions not to perform a cesarean section, not to resuscitate the newborn, or to proceed to palliative care after birth. All mothers with a contraindication to tocolysis (i.e. abruptio placentae, vaginal bleeding, hyperthermia, cord prolapsed or maternal pathology) were excluded $(n=24)$, as were women with $<2 \mathrm{hr}$ from PPROM diagnosis to delivery $(\mathrm{n}=47)$.

\section{French guidelines}

Guidelines from the National College of French Gynecologists and Obstetricians state that tocolysis can be administered after PPROM with uterine contractions up to 33 completed weeks' gestation. ${ }^{4}$ Recommended tocolytic agents are calcium-channel blockers (nifedipine, nicardipine), oxytocin-receptor blockers (atosiban) and, although rarely used, beta mimetics (salbutamol). Magnesium sulfate was not routinely used for tocolysis or neuroprotection in 2011.

\section{Main outcomes and exposition measures}

The primary outcome was survival to discharge without severe neonatal morbidity. ${ }^{22}$ Survival was defined as the number of children discharged alive from hospital relative to the number of fetuses alive at the time of PPROM. Severe neonatal morbidity was defined as any of the following: severe intraventricular haemorrhage (IVH) defined as IVH associated with ventricular dilatation (grade III IVH) and intraparenchymal hemorrhage (i.e., large unilateral parenchymal hyperdensity or large unilateral porencephalic cyst $)^{23}$; cystic periventricular 
203 leukomalacia (i.e., periventricular white matter echolucencies at ultrasonography) ${ }^{24}$; stages II

204 or III necrotizing enterocolitis according to Bell's staging ${ }^{25}$; stage 3 or greater retinopathy of

205

206

207

208

209

210

211

212

213

214

215

216

217

218

219

220

221

222 prematurity according to international classification ${ }^{26}$ and/or laser treatment; and severe bronchopulmonary dysplasia defined as requiring oxygen for at least 28 days in addition to the requirement of $30 \%$ or more oxygen and/or mechanical ventilator support or continuous positive airway pressure at 36 weeks' postmenstrual age. ${ }^{27}$

The secondary outcome was prolongation of gestation, defined as latency period (i.e., time from rupture to delivery) $\geq 48 \mathrm{hr}$. Prolongation of gestation after PPROM can induce prolonged fetal exposure to infection, with adverse consequences. We thus studied a third outcome: histological chorioamnionitis with or without funisitis (infection/inflammation of the fetal membranes with potential extension to the umbilical cord), diagnosed by the gold standard, i.e. histological examination of the placenta. ${ }^{28}$ The main exposure was the administration of any tocolytic treatment after PPROM diagnosis (coded as tocolysis vs no tocolysis).

\section{Definition of other studied factors}

Gestational age (GA) was determined as the best obstetrical estimate combining last menstrual period and first trimester ultrasonography assessment. Uterine contractions were assessed from uterine activity tracings recorded at admission. Administration of antenatal steroids was a binary variable categorized as "at least one injection" versus "no injection" so as to not introduce a temporality notion (i.e., complete course defined by two injections of betamethasone at a 24-hr interval) related to tocolysis effectiveness. Clinical chorioamnionitis was defined as maternal temperature $\geq 37.8^{\circ} \mathrm{C}\left(100^{\circ} \mathrm{F}\right)$ during delivery with any two of the following criteria: uterine tenderness, purulent or foul-smelling amniotic fluid, maternal tachycardia, fetal tachycardia, maternal leukocytosis $\geq 15,000$ cells $/ \mathrm{mm}^{3}$. Z-score birth weights were calculated from Gardosi's intrauterine growth curves corrected for sex and 
gestational age. ${ }^{29}$ Early-onset sepsis was diagnosed by positive bacteriology findings in blood or cerebrospinal fluid (confirmed infection) beginning during the first 3 days of life.

\section{Statistical analysis}

Categorical variables were compared by chi-square or Fisher's exact test as appropriate. Means and medians of quantitative variables were compared by Student's $t$ test and MannWhitney U test, respectively. All percentages and medians were weighted according to the duration of the recruitment periods by gestational age. Statistical significance was set at twotailed $\mathrm{p}<.05$.

We used a propensity-score analysis to minimize the indication bias in estimating the treatment effect. ${ }^{30}$ The propensity score was defined as the woman's probability of receiving tocolysis conditional on uterine contractions at admission and individual covariates. The first step in the analysis consisted of estimating the normalized score by using a logistic regression model with tocolysis as the dependent variable, regressed by baseline characteristics selected from the literature and clinical considerations, excluding covariates that might be affected by the treatment. ${ }^{31}$ We considered characteristic of the health center (type of maternity ward), maternal characteristics (age, country of birth), individual clinical factors (uterine contractions at admission, gestational age at PPROM, PPROM before hospitalization, fetal gender, presentation, and birth weight $<3^{\text {rd }}$ percentile of the normalized $\mathrm{z}$-score as a proxy for intrauterine growth restriction), and antenatal management (in utero transfer and administration of antenatal steroids or antibiotics), depending on the outcome. The propensity scores therefore take into account the possible indications for tocolysis administration (therapeutic or prophylactic). Gestational age at birth was not considered in the models because it can be a result of tocolysis administration. The second step in the analysis involved inverse probability of treatment weighting (IPTW), based on estimated propensity scores, to obtain a synthetic population in which treatment assignment is independent of measured baseline covariates, as 
confirmed by balance diagnostics. ${ }^{30,32}$ We finally estimated the association between tocolysis and outcomes by a logistic regression model within the weighted sample, obtaining odds ratios (ORs) and 95\% confidence intervals (95\% CIs) with robust standard errors.

Six sensitivity analyses were performed. We first investigated the association between the initial tocolysis drug used (oxytocin receptor antagonists, $\mathrm{n}=267$, or calcium-channel blockers, $n=287$, vs no tocolysis) and the three outcomes, with similar methodologies. Antenatal management, including tocolysis administration, might differ by GA at PPROM and induce a residual indication bias, so we analyzed women with PPROM at 26 to 31 completed weeks' gestation $(\mathrm{n}=549)$. The fourth sensitivity analysis focused on women who delivered at least twelve hours after PPROM $(n=686)$, to control for the low threshold initially chosen to define PPROM not resulting in including women with membranes ruptured during labor. Finally, we restricted the population to women with direct admission after PPROM (i.e. without in utero transfer) and with $(\mathrm{n}=115)$ or without $(\mathrm{n}=135)$ uterine contractions to investigate tocolysis consequences for specific subgroups.

The proportion of missing data ranged from $0 \%$ to $7.5 \%$ for each covariate, and missing data were considered missing at random. Multiple imputation involved use of all baseline variables and outcomes of the propensity-score model. A propensity score was estimated for each of the 30 imputed datasets generated, and results were pooled for a final analysis according to Rubin's rules.

At the conventional two-tailed significance level of 0.05 , and based on the fixed sample size, our study had $80 \%$ statistical power to show an OR of 1.1 quantifying the association between tocolysis and improved survival without major morbidity. Data were analyzed by use of Stata/SE 13.0 (StataCorp LP, College Station, TX, USA). 


\section{Results}

Among the 803 women with PPROM at 24 to 32 weeks' gestation, with singletons alive at PPROM and without contraindication to tocolysis, 596 (weighted percentage 73.4\%) received tocolysis after PPROM and 207 (weighted percentage 26.6\%) did not (Figure 1). The proportion of participants who received tocolysis was similar for each subgroup of gestational age at PPROM: $76.6 \%$ at 24 to 26 weeks' gestation, $74.1 \%$ at 27 to 29 weeks and $71.8 \%$ at 30 to 32 weeks $(\mathrm{p}=.55)$.

Maternal, obstetric and center characteristics with and without tocolysis administration are presented in Table 1. Treatment groups did not differ in median gestational age at PPROM and at birth. Median latency durations were similar: 6 versus 5 days without and with tocolysis $(\mathrm{p}=.26)$. Women who were transferred from another hospital more frequently received tocolysis, as had women with uterine contractions at admission. Antibiotics and antenatal steroids use were respectively $>95 \%$ and $>89 \%$, whatever the treatment group.

In total, 619 children survived until discharge without severe morbidity (weighted percentage 85.9\% [95\% CI 83.1-88.3]); for 597 (weighted percentage 75.7\% [71.4-79.5]), the latency period was prolonged by $\geq 48 \mathrm{hr}$ (Table 2). When placental examination was performed $(n=494)$, histological chorioamnionitis was diagnosed in 280 cases (weighted percentage 49.5\% [43.5-55.5]). There was no association between the tocolysis group and these three outcomes, nor when stratifying by gestational age at PPROM. The risk of in utero fetal demise after PPROM was similar in both groups $(1.0 \%$ vs $1.0 \%, \mathrm{p}=.96)$. The incidence of early-onset sepsis, severe cerebral lesion, severe bronchopulmonary dysplasia, necrotizing enterocolitis and retinopathy did not differ by treatment group (Table A.1).

Propensity scores were calculated for each woman and for each outcome. Mean propensity score and covariates were balanced across treatment and comparison groups within the 5 blocks of propensity scores. Moreover, standardized differences in the weighted samples were 
less than $10 \%$. These diagnostic assessments suggest that for each outcome, IPTW created a sample in which the distributions of baseline-measured covariates were similar with and without tocolysis. Tocolysis after PPROM was not associated with survival at discharge without severe morbidity or latency prolonged by $\geq 48 \mathrm{hr}$ ( $\mathrm{OR}=1.01$ [95\% CI $0.94-1.09$ ] and 1.03 [0.95-1.11], respectively) (Table 3).

To assess whether tocolysis could increase intra-uterine inflammation, we investigated the association of tocolysis and histological chorioamnionitis in the subgroup of 494 women with placental examination and found no increase in histological chorioamnionitis with tocolysis $(\mathrm{OR}=1.03[0.92-1.17])$.

The initial tocolytic agents were mainly oxytocin receptor antagonists (267 women) and calcium-channel blockers (287 women). As compared with no tocolysis, the type of initial drug was not associated with the three outcomes (Table A.2).

We performed a sensitivity analysis including 549 women with PPROM at 26 to 31 weeks' gestation, of whom 413 (weighted percentage 75.4\%) received tocolysis, and found no association between tocolysis and survival at discharge without severe morbidity, latency prolonged by $\geq 48 \mathrm{hr}$ and histological chorioamnionitis ( $\mathrm{OR}=1.06$ [0.98-1.15], 1.04 [0.951.14], and 1.03 [0.88-1.19], respectively) (Table 3). We also investigated a subgroup of 686 women who delivered at least $12 \mathrm{hr}$ after rupture of membranes, of whom 514 (weighted percentage 73.5\%) received tocolysis, and found no association between tocolysis and the three outcomes $(\mathrm{OR}=1.01[0.93-1.10], 1.05[0.97-1.13]$ and 1.05 [0.92-1.20], respectively) (Table 3). Among women with direct admission after PPROM, respectively 68.5\% and 51.3\% had therapeutic or prophylactic tocolysis. In these specific subgroups, there was no association between tocolysis and the three outcomes (Table A.3). 


\section{Comment}

Main findings

Our study shows that in cases of preterm births related to PPROM, tocolysis administration is not associated with survival at discharge without severe morbidity or with delivery delayed by $\geq 48 \mathrm{hr}$ after PPROM. Additionally, the rate of histological chorioamnionitis is similar with and without tocolysis after PPROM.

\section{Strengths and limitations}

Strengths of our study include a large sample of women with contemporary obstetric management including a high rate of antenatal steroids and antibiotics. We believe our study findings allow for an assessment of routine clinical management practices in the paucity of data from well-constructed and up-to-date randomized control trials. Indeed, currently available trials specifically addressing tocolysis administration after PPROM were published more than 20 years ago, ${ }^{9,10,12,14-16,33,34}$ had small sample size (6 to 81 patients), or featured bias (e.g. performance and detection biases with no blinding of the participants or researchers, ${ }^{12-16}$ or reporting bias with outcomes not pre-specified or not explicitly stated ${ }^{9,16}$ ). Antibiotics and steroids were not consistently administered resulting in a substantial limitation in the reliability and external validity of the results. In contrast to most randomized trials, ${ }^{10,14,15,18}$ we included all women for whom tocolysis was potentially useful, including those with regular contractions.

Neonatal prognosis was considered the relevant clinical outcome to set as a primary outcome. Indeed, prolongation of gestation is not an objective but a step in the pathway to improve perinatal morbidity and mortality. Randomized trials designed to show a significant difference in latency duration as a primary outcome can be underpowered to find a significant difference in neonatal mortality or morbidity. ${ }^{9,11,12,14,15}$ 
This study was, however, limited by the design of the EPIPAGE 2 cohort: treatment assignment was not random with the observational data. A new randomized controlled trial would help define the best management, but in these anxiety-provoking situations, trials are difficult to achieve. For illustration, in the APOSTEL IV trial, 50 women were randomized in 27 months while the expected number was $120 .{ }^{18}$ With these observational data, we compared treatment strategies under the usual conditions, simulating a hypothetical pragmatic randomized trial. ${ }^{35}$ To address the indication bias, we used a propensity-score method to obtain unbiased estimates of average treatment effects and followed the most recent best practices for the use of IPTW. ${ }^{32}$ This method provided a way to balance measured covariates across treated and control groups. The precise indication for tocolysis was not specified in the EPIPAGE 2 cohort study. Tocolysis can be given to patients with contractions after PPROM (therapeutic tocolysis) or without contractions (prophylactic tocolysis). We thus included in the propensity score the variable indicating contractions at admission and performed sensitivity analyses by stratifying on contractions at admission, with consistent findings.

We considered that within two hours after PPROM diagnosis, the obstetrics team had enough time to give tocolysis if deemed necessary. However, choosing a fairly low threshold between PPROM diagnosis and birth may have induced a selection bias by including women with membranes ruptured during labor. We therefore tested the robustness of our analysis by using a 12-hr threshold, which gave similar results.

Another limitation involves the truncated population for cases of PPROM delivered after 35 weeks. Late-preterm births were indeed not considered in the EPIPAGE 2 design. Therefore, we studied only women with PPROM at 24 to 32 weeks and likely missed only a very few births with the longest latency durations and the best prognosis. ${ }^{36}$

Placental histology was not systematically performed. Absence of examination was associated with late gestational age, absence of clinical chorioamnionitis and delivery in a type 2 
maternity ward. Data were not missing at random, so we did not perform multiple imputation.

It is possible that we missed examinations for the healthiest infants and as a result slightly overestimated the association between tocolysis administration and chorioamnionitis.

\section{Interpretation}

Our main neonatal finding is in line with recent publications, ${ }^{8,18}$ including a meta-analysis (8 randomized controlled trials, 408 women with PPROM) which showed that tocolysis was not associated with neonatal outcome improvement as compared with no tocolysis. ${ }^{8}$ However, our results bring further explanations for this negative result, relying on the lack of difference in the prolongation of pregnancy and on the incidence of histological chorioamnionitis unrelated to tocolysis use. These two last findings contrast with the conclusions of the meta-analysis, and may be possibly explained by the beneficial impact of antibiotic administration ${ }^{7}$ widely used in our sample for women with and without tocolysis or the use of a different definition for chorioamnionitis (clinical vs histological).

Finally, it should be noted that the magnitude of the between-group difference was small and with limited clinical relevance. Tocolysis might thus be considered an ineffective intervention in the setting of PPROM. ${ }^{18}$

Although most women presenting PPROM and delivering prematurely received tocolysis, the treatment was not associated with neonatal outcome or prolonged gestation by $\geq 48 \mathrm{hr}$. These results do not support tocolytic therapy for women with PPROM and emphasize the need for a large randomized controlled trial designed to study the impact of tocolysis on neonatal outcomes. 
Acknowledgements: We are grateful to the participating children and their families and to all maternity and neonatal units in France. The authors thank Laura Smales for editorial assistance and acknowledge the collaborators of the EPIPAGE2 Obstetric writing group:

Catherine Arnaud, MD, PhD (Research Unit on Perinatal Epidemiology, Childhood Disabilities and Adolescent Health, INSERM UMR 1027, Paul Sabatier University, Toulouse, France), Bruno Carbonne, MD (Department of Obstetrics and Gynecology, Princess Grace Hospital, Monaco), Thierry Debillon, MD, PhD (Department of Neonatal Pediatrics, University Hospital, Grenoble, France), Pierre Delorme, MD (Inserm UMR 1153, Obstetrical, Perinatal and Pediatric Epidemiology Research Team (Epopé), Center for Epidemiology and Statistics Sorbonne Paris Cité, DHU Risks in pregnancy, Paris Descartes University, Department of Obstetrics and Gynecology, Cochin, Broca, Hôtel Dieu Hospital, AP-HP, Paris, France), Claude D'Ercole, MD (Department of Obstetrics and Gynecology, Nord Hospital, Assistance Publique des Hôpitaux de Marseille (AP-HM), Aix Marseille Université, AMU, Marseille, France), Caroline Diguisto, MD (Inserm UMR 1153, Obstetrical, Perinatal and Pediatric Epidemiology Research Team (Epopé), Center for Epidemiology and Statistics Sorbonne Paris Cité, DHU Risks in pregnancy, Paris Descartes University, Maternité Olympe de Gouges, University Francois Rabelais, Tours, France), Michel Dreyfus, MD (Department of Gynecology and Obstetrics, University Hospital, Caen, France), Laurence Foix L'Hélias, MD, PhD (Inserm UMR 1153, Obstetrical, Perinatal and Pediatric Epidemiology Research Team (Epopé), Center for Epidemiology and Statistics Sorbonne Paris Cité, DHU Risks in pregnancy, Paris Descartes University, Sorbonne Universités, UPMC Univ Paris 06, IFD, 4 Place Jussieu, 75252 PARIS cedex 05, Paris, France, Department of Neonatal Pediatrics, Trousseau Hospital, AP-HP, Paris, France), Géraldine Gascoin, MD, PhD (Department of Neonatal Medicine, Angers University Hospital, Angers, France), Adrien Gaudineau, MD (Department of Obstetrics and Gynecology, Hautepierre Hospital, Strasbourg, France), Bruno Langer, MD (Department of Obstetrics and Gynecology, Hautepierre Hospital, Strasbourg, France), Emeline Maisonneuve, MD (Department of Obstetrics and Gynecology, Trousseau Hospital, APHP, Paris, France), Loïc Sentilhes, MD, $\mathrm{PhD}$ (Department of Obstetrics and Gynecology, Bordeaux University Hospital, Bordeaux, France), Damien Subtil, MD, PhD (Department of Obstetrics and Gynecology, Jeanne de Flandre Hospital, Lille, France), Barthélémy Tosello, MD (Department of Neonatology, Assistance Publique Hopitaux de Marseille, Marseille, France), Aurélie Garbi, MD (Department of Neonatology, Assistance Publique Hopitaux de Marseille, Marseille, France), Héloïse Torchin, MD (Inserm UMR 1153, Obstetrical, Perinatal and Pediatric Epidemiology Research Team (Epopé), Center for Epidemiology and Statistics Sorbonne Paris Cité, DHU Risks in pregnancy, Paris Descartes University), Monique Kaminski, MSc (Inserm UMR 1153, Obstetrical, Perinatal and Pediatric Epidemiology Research Team (Epopé), Center for Epidemiology and Statistics Sorbonne Paris Cité, DHU Risks in pregnancy, Paris Descartes University), Norbert Winer, MD, PhD (Department of Obstetrics and Gynecology, University Hospital, INRA, UMR 1280 Physiologie des adaptations nutritionnelles, Nantes, France), Jean-Christophe Rozé, MD, PhD (Department of Neonatal Medicine, Nantes University Hospital, Nantes, France2Epidémiologie Clinique, Centre d'Investigation Clinique (CIC004), Nantes University Hospital, Nantes, France), Jennifer Zeitlin (Inserm UMR 1153, Obstetrical, Perinatal and Pediatric Epidemiology Research Team (Epopé), Center for Epidemiology and Statistics Sorbonne Paris Cité, DHU Risks in pregnancy, Paris Descartes University).

All the collaborators of the EPIPAGE2 Obstetric writing group have no conflict of interest or compensation in relation with this article to disclose. All of them consented to such acknowledgment. 


\section{Contribution to authorship:}

\section{Study supervision: GK}

Study concept: EL, GK

Design of the present study: EL, GK.

Acquisition, analysis and interpretation of data: All authors Statistical analysis: EL, GK

Drafting of the manuscript: EL, GK

Critical revision of the manuscript for important intellectual content: All authors Final approval of the version to be published: All authors

Agreement to be accountable for all aspects of the work: All authors 
481

482 1. Mercer BM. Preterm premature rupture of the membranes. Obstet Gynecol. 2003

\section{References:} Jan;101(1):178-93.

484

485

2. Goldenberg RL, Culhane JF, Iams JD, Romero R. Epidemiology and causes of preterm birth. Lancet. 2008 Jan 5;371(9606):75-84.

486 3. Dammann O, Leviton A, Gappa M, Dammann CEL. Lung and brain damage in 487 preterm newborns, and their association with gestational age, prematurity subgroup, 488 infection/inflammation and long term outcome. BJOG Int J Obstet Gynaecol. 2005 Mar 489 1;112:4-9.

4. CNGOF. Recommandations pour la pratique clinique RPM 1999 [Internet]. [cited 2014 Jun 17]. Available from: http://www.cngof.asso.fr/D_PAGES/PURPC_06.HTM

5. ACOG. Practice Bulletin No. 172: Premature Rupture of Membranes. Obstet Gynecol. 2016 Oct;128(4):e165-177.

6. Roberts D, Dalziel SR. Antenatal corticosteroids for accelerating fetal lung maturation for women at risk of preterm birth. In: Cochrane Database of Systematic Reviews [Internet]. John Wiley \& Sons, Ltd; 2006 [cited 2016 Aug 11]. Available from: http://onlinelibrary.wiley.com.gate2.inist.fr/doi/10.1002/14651858.CD004454.pub2/abstract 7. Kenyon S, Boulvain M, Neilson JP. Antibiotics for preterm rupture of membranes. Cochrane Database Syst Rev. 2013;12:CD001058.

8. Mackeen AD, Seibel-Seamon J, Muhammad J, Baxter JK, Berghella V. Tocolytics for preterm premature rupture of membranes. Cochrane Database Syst Rev. 2014;2:CD007062.

9. Christensen KK, Ingemarsson I, Leideman T, Solum T, Svenningsen N. Effect of ritodrine on labor after premature rupture of the membranes. Obstet Gynecol. 1980 Feb;55(2):187-90. 
505 10. Dunlop PDM, Crowley PA, Lamont RF, Hawkins DF. Preterm ruptured membranes, 506 no contractions. J Obstet Gynaecol. 1986 Jan 1;7(2):92-6.

507 11. Ehsanipoor RM, Shrivastava VK, Lee RM, Chan K, Galyean AM, Garite TJ, et al. A 508 randomized, double-masked trial of prophylactic indomethacin tocolysis versus placebo in 509 women with premature rupture of membranes. Am J Perinatol. 2011 Jun;28(6):473-8.

510 12. Garite TJ, Keegan KA, Freeman RK, Nageotte MP. A randomized trial of ritodrine 511 tocolysis versus expectant management in patients with premature rupture of membranes at 512 25 to 30 weeks of gestation. Am J Obstet Gynecol. 1987 Aug;157(2):388-93.

13. Laohapojanart N, Soorapan S, Wacharaprechanont T, Ratanajamit C. Safety and efficacy of oral nifedipine versus terbutaline injection in preterm labor. J Med Assoc Thail 515 Chotmaihet Thangphaet. 2007 Nov;90(11):2461-9.

516 14. Levy DL, Warsof SL. Oral ritodrine and preterm premature rupture of membranes. 517 Obstet Gynecol. 1985 Nov;66(5):621-3.

518 15. Matsuda Y, Ikenoue T, Hokanishi H. Premature Rupture of the Membranes; 519 Aggressive versus Conservative Approach: Effect of Tocolytic and Antibiotic Therapy. 520 Gynecol Obstet Invest. 1993;36(2):102-7.

521 16. Weiner CP, Renk K, Klugman M. The therapeutic efficacy and cost-effectiveness of 522 aggressive tocolysis for premature labor associated with premature rupture of the membranes. Am J Obstet Gynecol. 1988 Jul;159(1):216-22.

524 17. Combs CA, McCune M, Clark R, Fishman A. Aggressive tocolysis does not prolong 525 pregnancy or reduce neonatal morbidity after preterm premature rupture of the membranes. 526 Am J Obstet Gynecol. 2004 Jun;190(6):1723-1728-1731.

527 18. Nijman TAJ, van Vliet EOG, Naaktgeboren CA, Oude Rengerink K, de Lange TS, 528 Bax CJ, et al. Nifedipine versus placebo in the treatment of preterm prelabor rupture of 529 membranes: a randomized controlled trial: Assessment of perinatal outcome by use of 
530 tocolysis in early labor-APOSTEL IV trial. Eur J Obstet Gynecol Reprod Biol. 2016 531 Oct;205:79-84.

532 19. Fox NS, Gelber SE, Kalish RB, Chasen ST. Contemporary practice patterns and 533 beliefs regarding tocolysis among u.s. Maternal-fetal medicine specialists. Obstet Gynecol. $5342008 \mathrm{Jul} ; 112(1): 42-7$.

535 20. Couteau C, Haumonté J-B, Bretelle F, Capelle M, D’Ercole C. Pratiques en France de 536 prise en charge des ruptures prématurées des membranes. J Gynécologie Obstétrique Biol 537 Reprod. 2013 Feb;42(1):21-8.

538 21. Ancel P-Y, Goffinet F, EPIPAGE 2 Writing Group. EPIPAGE 2: a preterm birth 539 cohort in France in 2011. BMC Pediatr. 2014;14:97.

540 22. Ancel P, Goffinet F, and the EPIPAGE-2 Writing Group. Survival and morbidity of 541 preterm children born at 22 through 34 weeks' gestation in France in 2011: Results of the 542 epipage-2 cohort study. JAMA Pediatr. 2015 Mar 1;169(3):230-8.

543 23. Papile L-A, Burstein J, Burstein R, Koffler H. Incidence and evolution of 544 subependymal and intraventricular hemorrhage: A study of infants with birth weights less 545 than 1,500 gm. J Pediatr. 1978 Apr 1;92(4):529-34.

546 24. Volpe JJ. Brain injury in premature infants: a complex amalgam of destructive and 547 developmental disturbances. Lancet Neurol. 2009 Jan;8(1):110-24.

548 25. Bell MJ, Ternberg JL, Feigin RD, Keating JP, Marshall R, Barton L, et al. Neonatal 549 necrotizing enterocolitis. Therapeutic decisions based upon clinical staging. Ann Surg. 1978 550 Jan;187(1):1-7.

551 26. Classification of Retinopathy of Prematurity*. The international classification of 552 retinopathy of prematurity revisited. Arch Ophthalmol. 2005 Jul 1;123(7):991-9.

553 27. Jobe AH, Bancalari E. Bronchopulmonary Dysplasia. Am J Respir Crit Care Med. 5542001 Jun 1;163(7):1723-9. 
555 28. Higgins RD, Saade G, Polin RA, Grobman WA, Buhimschi IA, Watterberg K, et al.

556 Evaluation and Management of Women and Newborns With a Maternal Diagnosis of 557 Chorioamnionitis: Summary of a Workshop. Obstet Gynecol. 2016 Mar;127(3):426-36.

558 29. Gardosi J, Chang A, Kalyan B, Sahota D, Symonds EM. Customised antenatal growth 559 charts. The Lancet. 1992 Feb 1;339(8788):283-7.

560 30. Austin PC. An Introduction to Propensity Score Methods for Reducing the Effects of 561 Confounding in Observational Studies. Multivar Behav Res. 2011 May;46(3):399-424.

562 31. Garrido MM, Kelley AS, Paris J, Roza K, Meier DE, Morrison RS, et al. Methods for 563 Constructing and Assessing Propensity Scores. Health Serv Res. 2014 Oct 1;49(5):1701-20.

564 32. Austin PC, Stuart EA. Moving towards best practice when using inverse probability of 565 treatment weighting (IPTW) using the propensity score to estimate causal treatment effects in 566 observational studies. Stat Med. 2015 Dec 10;34(28):3661-79.

567 33. Decavalas G, Mastrogiannis D, Papadopoulos V, Tzingounis V. Short-term versus 568 long-term prophylactic tocolysis in patients with preterm premature rupture of membranes. 569 Eur J Obstet Gynecol Reprod Biol. 1995 Apr;59(2):143-7.

570 34. How HY, Cook CR, Cook VD, Miles DE, Spinnato JA. Preterm Premature Rupture of 571 Membranes: Aggressive Tocolysis Versus Expectant Management. J Matern Fetal Neonatal 572 Med. 1998 Jan 1;7(1):8-12.

573 35. Hernán MA, Robins JM. Using Big Data to Emulate a Target Trial When a 574 Randomized Trial Is Not Available. Am J Epidemiol. 2016 Apr 15;183(8):758-64.

575 36. Lieman JM, Brumfield CG, Carlo W, Ramsey PS. Preterm Premature Rupture of 576 Membranes: Is There an Optimal Gestational Age for Delivery?: Obstet Gynecol. 2005 577 Jan;105(1):12-7.

578 
580

581

582

583

584

585

586

587

588

589

590

591

592

593

594

595 admitted directly after PPROM, with and without contractions 

administration after preterm premature rupture of membranes (PPROM)

\begin{tabular}{|c|c|c|c|}
\hline Characteristics & $\begin{array}{l}\text { No tocolysis } \\
(\mathrm{n}=207)\end{array}$ & $\begin{array}{l}\text { Tocolysis } \\
(\mathrm{n}=596)\end{array}$ & $P$ value \\
\hline \multicolumn{4}{|l|}{ Maternal characteristics } \\
\hline Age (years), median (IQR) (n=802) & $30(26-39)$ & $29(26-33)$ & .11 \\
\hline Born in France or Europe $(\mathrm{n}=786)$ & $149(75.9)$ & $463(78.7)$ & .56 \\
\hline Married ( $\mathrm{n}=787)$ & $173(89.9)$ & $521(90.5)$ & .83 \\
\hline Primiparity $(\mathrm{n}=797)$ & $98(48.4)$ & $280(51.9)$ & .54 \\
\hline \multicolumn{4}{|l|}{ Obstetric characteristics and management } \\
\hline PPROM before hospitalization ( $\mathrm{n}=803$ ) & $155(81.3)$ & $515(88.3)$ & .04 \\
\hline Contractions at admission $(\mathrm{n}=759)$ & $71(33.0)$ & $249(44.1)$ & .05 \\
\hline Gestational age at PPROM (WG) $(\mathrm{n}=803)$, median (IQR) & $30(27-32)$ & $30(27-31)$ & .83 \\
\hline Latency duration (days), median (IQR) $(\mathrm{n}=787)$ & $6(2.0-12.0)$ & $5(1.9-11.5)$ & .26 \\
\hline Gestational age at birth (WG) $(\mathrm{n}=803)$, median (IQR) & $31(29-33)$ & $31(29-32)$ & .99 \\
\hline In utero transfer $(\mathrm{n}=803)$ & $72(27.4)$ & $415(63.3)$ & $<.001$ \\
\hline Antibiotics $(\mathrm{n}=803)$ & $193(95.8)$ & $579(97.0)$ & .43 \\
\hline Antenatal steroids $(\mathrm{n}=803)$ & $179(89.0)$ & $552(89.0)$ & .99 \\
\hline Magnesium sulfate $(\mathrm{n}=787)$ & $10(3.2)$ & $34(4.0)$ & .53 \\
\hline Type of labor $(\mathrm{n}=801)$ & & & .002 \\
\hline Spontaneous labor & $101(42.4)$ & $357(61.4)$ & \\
\hline Induction of labor & $25(18.9)$ & $32(8.1)$ & \\
\hline Cesarean before labor & $80(38.7)$ & $206(30.5)$ & \\
\hline Mode of delivery ( $\mathrm{n}=798)$ & & & .11 \\
\hline Vaginal delivery & $94(44.2)$ & $300(55.9)$ & \\
\hline Cesarean before labor & $80(38.8)$ & $206(30.6)$ & \\
\hline Cesarean during labor & $31(17.0)$ & $87(13.5)$ & \\
\hline Cephalic presentation $(n=785)$ & $134(73.7)$ & $413(72.4)$ & .79 \\
\hline Male fetus $(n=803)$ & $116(57.9)$ & $325(54.3)$ & .51 \\
\hline Birth weight $\leq 3^{\text {rd }}$ percentile of the normalized $z$-score $(n=802)$ & $18(8.4)$ & $35(5.4)$ & .26 \\
\hline Clinical chorioamnionitis $(\mathrm{n}=792)$ & $16(4.7)$ & $40(5.6)$ & .59 \\
\hline \multicolumn{4}{|l|}{ Maternity unit characteristics } \\
\hline Type of maternity unit $(n=803)$ & & & .30 \\
\hline Type 1 (no neonatal department) & $2(2.0)$ & $4(0.4)$ & \\
\hline Type 2 (with neonatal department) & $30(20.6)$ & $56(23.2)$ & \\
\hline Type 3 (with neonatal intensive care department) & $175(77.4)$ & $536(76.4)$ & \\
\hline
\end{tabular}

608

609

610

611

612

613

614

615

616

Data are $\mathrm{n}(\%)$ unless indicated. Percentages are weighted by recruitment period.

IQR, interquartile range; WG, weeks' gestation.

The two groups were compared by Mann Whitney test for medians and chi-square or Fisher's exact test for categorical variables. 
618

619

620

\begin{tabular}{l}
\hline $\begin{array}{l}\text { Outcome } \\
\text { GA at PPROM (wk) }\end{array}$ \\
\hline Survival without severe \\
morbidity \\
$24-26$ \\
$27-29$ \\
$30-32$
\end{tabular}

Latency prolonged by $\geq 48 \mathrm{hr}$

24-26

27-29

30-32

Histological chorioamnionitis or funisitis

24-26

27-29

30-32

$\begin{array}{ll}\text { Total } & \text { No tocolysis } \\ \mathrm{n} / \mathrm{N}(\%) & \mathrm{n} / \mathrm{N}(\%)\end{array}$

$619 / 785\left(85.9^{\mathrm{a}}\right)$

$150 / 262(62.4)$

$226 / 258(89.0)$

$243 / 265(93.5)$

$597 / 803\left(75.7^{\mathrm{a}}\right)$
$220 / 272(83.6)$
$215 / 262(84.1)$
$162 / 269(68.4)$

$280 / 494^{\mathrm{b}}\left(49.5^{\mathrm{a}}\right)$

$130 / 198(63.9)$

$96 / 162(56.3)$ $54 / 134(37.0)$

${ }^{a}$ Percentages are weighted by recruitment period.

${ }^{b}$ Among the histological examinations carried out.

The two groups were compared by chi-square or Fisher's exact test.

$\mathrm{GA}$, gestational age

$36 / 67(56.3)$

$57 / 63(92.1)$

$63 / 73(89.2)$

$156 / 207\left(83.9^{\mathrm{a}}\right) \quad 463 / 596\left(86.7^{\mathrm{a}}\right) \quad .39$

$114 / 195(64.3) \quad .26$

$169 / 195(88.0) \quad .35$

$180 / 192(95.2) \quad .14$

$\begin{array}{lll}147 / 207\left(77.4^{\mathrm{a}}\right) & 450 / 596\left(75.1^{\mathrm{a}}\right) & .59 \\ 52 / 69(76.9) & 168 / 203(85.7) & .09 \\ 49 / 64(80.4) & 166 / 198(85.4) & .35 \\ 46 / 74(76.2) & 116 / 195(65.4) & .15\end{array}$

621

622

623

624

625

626

627

628

629

630

631

632

633

634

635

636

637

638 
643

644

645

646

647

648

649

650

651

652

653

654

655

656

657

658

659

660

661

662

663

664

Table 3: Association between tocolysis administration after PPROM and survival without severe morbidity, latency prolonged by $\geq 48 \mathrm{hr}$ and histological chorioamnionitis after inverse probability of treatment weighting

\begin{tabular}{|c|c|c|c|}
\hline Outcome & $\begin{array}{l}\text { Whole } \\
\text { population }\end{array}$ & $\begin{array}{l}\text { PPROM at } 26 \\
\text { to } 31 \mathrm{WG}\end{array}$ & Latency $\geq 12 \mathrm{hr}$ \\
\hline & OR $(95 \% \mathrm{CI})$ & OR $(95 \% \mathrm{CI})$ & OR $(95 \% \mathrm{CI})$ \\
\hline Survival without severe morbidity ${ }^{a}$ & $(n=803)^{d}$ & $(n=549)^{d}$ & $(n=686)^{d}$ \\
\hline No tocolysis & Ref & Ref & Ref \\
\hline Tocolysis & $1.01(0.94-1.09)$ & $1.06(0.98-1.15)$ & $1.01(0.93-1.10)$ \\
\hline Latency prolonged by $\geq 48 \mathrm{hr}^{\mathrm{b}}$ & $(\mathrm{n}=803)^{\mathrm{d}}$ & $(\mathrm{n}=549)^{\mathrm{d}}$ & $(\mathrm{n}=686)^{\mathrm{d}}$ \\
\hline No tocolysis & Ref & Ref & Ref \\
\hline Tocolysis & $1.03(0.95-1.11)$ & $1.04(0.95-1.14)$ & $1.05(0.97-1.13)$ \\
\hline $\begin{array}{l}\text { Histological chorioamnionitis or } \\
\text { funisitis }^{c}\end{array}$ & $(\mathrm{n}=494)^{\mathrm{e}}$ & $(\mathrm{n}=323)^{\mathrm{e}}$ & $(n=429)^{e}$ \\
\hline No tocolysis & Ref & Ref & Ref \\
\hline Tocolysis & $1.03(0.92-1.17)$ & $1.03(0.88-1.19)$ & $1.05(0.92-1.20)$ \\
\hline
\end{tabular}

WG: weeks' gestation

${ }^{a}$ Covariates used to estimate the propensity score: type of maternity unit, country of mother's birth, maternal age, gestational age at PPROM, PPROM before hospitalization, presence of contractions at admission, in utero transfer, antenatal steroids, antibiotics, fetal gender, presentation, birth weight $<3^{\text {rd }}$ percentile of the normalized z-score.

${ }^{\mathrm{b}}$ Covariates used to estimate the propensity score: type of maternity unit, maternal age, gestational age at PPROM, PPROM before hospitalization, presence of contractions at admission, in utero transfer, antenatal steroids, antibiotics, fetal gender, presentation, birth weight $<3^{\text {rd }}$ percentile of the normalized z-score.

c Covariates used to estimate the propensity score: type of maternity unit, maternal age, gestational age at PPROM, PPROM before hospitalization, presence of contractions at admission, in utero transfer, antenatal steroids, antibiotics, presentation.

${ }^{\mathrm{d}}$ Obtained after multiple imputation.

${ }^{\mathrm{e}}$ For performed placental examination. 
666 667

Table A.1: Detailed neonatal outcomes without and with tocolysis administration

\begin{tabular}{cllll}
\hline $\begin{array}{c}\text { Outcome } \\
\text { GA at PPROM (wk) }\end{array}$ & Total & No tocolysis & Tocolysis & p.value \\
\hline Survival at discharge & $\mathrm{n} / \mathrm{N}\left(\%^{\mathrm{a}}\right)$ & $\mathrm{n} / \mathrm{N}\left(\%^{\mathrm{a}}\right)$ & $\mathrm{n} / \mathrm{N}\left(\%^{\mathrm{a}}\right)$ & \\
$24-26$ & $718 / 803(93.9)$ & $182 / 207(93.4)$ & $536 / 596(94.2)$ & .62 \\
$27-29$ & $202 / 272(77.4)$ & $48 / 69(71.2)$ & $154 / 203(79.3)$ & .16 \\
$30-32$ & $249 / 262(95.6)$ & $61 / 64(96.1)$ & $188 / 198(95.4)$ & .81 \\
Early-onset sepsis $^{\mathbf{b}}$ & $267 / 269(99.7)$ & $73 / 74(99.4)$ & $194 / 195(99.8)$ & .50 \\
$24-26$ & $31 / 766(3.4)$ & $9 / 193(4.4)$ & $22 / 573(3.0)$ & .49 \\
$27-29$ & $10 / 242(3.7)$ & $2 / 57(3.2)$ & $8 / 185(3.8)$ & .82 \\
$30-32$ & $11 / 259(5.2)$ & $4 / 64(5.2)$ & $7 / 195(5.2)$ & .99 \\
Severe cerebral lesion ${ }^{\mathbf{c}, \mathbf{d}}$ & $10 / 265(2.4)$ & $3 / 72(4.3)$ & $7 / 193(1.6)$ & .23 \\
$24-26$ & $32 / 717(3.5)$ & $11 / 182(4.8)$ & $21 / 535(3.0)$ & .34 \\
$27-29$ & $15 / 202(6.3)$ & $6 / 48(11.2)$ & $9 / 154(5.0)$ & .11 \\
$30-32$ & $8 / 248(2.8)$ & $3 / 61(4.1)$ & $5 / 187(2.4)$ & .47 \\
Severe bronchopulmonary & $9 / 267(2.9)$ & $2 / 73(3.7)$ & $7 / 194(2.6)$ & .72 \\
dysplasia $^{\mathbf{c}}$ & $30 / 699(2.4)$ & $4 / 177(1.3)$ & $26 / 522(2.8)$ & .13 \\
$24-26$ & & & & \\
$27-29$ & $21 / 190(9.2)$ & $3 / 45(6.6)$ & $18 / 145(9.9)$ & .51 \\
$30-32$ & $7 / 246(2.5)$ & $0 / 60(0.0)$ & $7 / 186(3.4)$ & .13 \\
Necrotizing enterocolitis ${ }^{c}$ & $2 / 263(0.3)$ & $1 / 72(0.6)$ & $1 / 191(0.2)$ & .50 \\
$24-26$ & $16 / 716(2.2)$ & $6 / 182(3.5)$ & $10 / 534(1.8)$ & .32 \\
$27-29$ & $4 / 200(1.9)$ & $1 / 48(1.9)$ & $3 / 152(1.9)$ & .98 \\
$30-32$ & $4 / 249(1.4)$ & $0 / 61(0.0)$ & $4 / 188(1.9)$ & .24 \\
${\text { Retinopathy of prematurity }{ }^{\mathbf{c}}}_{24-26}$ & $7 / 267(2.7)$ & $5 / 73(5.4)$ & $3 / 194(1.7)$ & .19 \\
$27-29$ & $6 / 202(2.6)$ & $2 / 182(0.7)$ & $5 / 536(0.5)$ & .63 \\
$30-32$ & $0 / 246(0.0)$ & $1 / 48(2.5)$ & $5 / 154(2.6)$ & .99 \\
- & $1 / 267(0.2)$ & $1 / 73(0.0)$ & $0 / 188(0.0)$ & - \\
& & & $0 / 194(0.0)$ & .11 \\
\hline
\end{tabular}

GA, gestational age

669 a Percentages are weighted by recruitment period.

$670 \quad{ }^{\mathrm{b}}$ Among infants transfered to a neonatal intensive care unit

$671{ }^{c}$ Among infants alive at discharge

$672{ }^{\mathrm{d}}$ Severe cerebral lesion include grade III intraventricular haemorrhage, intraparenchymal hemorrhage or cystic

673 periventricular leukomalacia

674

675

676

677

678

679

680

681

682

683 
Table A.2: Association between the initial tocolytic drug after PPROM and survival without severe morbidity, latency prolonged by $\geq 48 \mathrm{hr}$ and histological chorioamnionitis after inverse probability of treatment weighting

\begin{tabular}{lll}
\hline Outcome & $\begin{array}{l}\text { Oxytocin } \\
\text { receptor } \\
\text { antagonists }\end{array}$ & $\begin{array}{l}\text { Calcium- } \\
\text { channel } \\
\text { blockers }\end{array}$ \\
\hline & OR $(95 \% \mathrm{CI})$ & OR $(95 \% \mathrm{CI})$ \\
\hline $\begin{array}{l}\text { Survival without severe } \\
\text { morbidity }\end{array}$ & $(\mathrm{n}=474)^{\mathrm{d}}$ & $(\mathrm{n}=494)^{\mathrm{d}}$ \\
$\begin{array}{l}\text { No tocolysis } \\
\text { Tocolysis }\end{array}$ & Ref & Ref \\
& $1.01(0.92-1.11)$ & $1.03(0.96-1.11)$ \\
$\begin{array}{l}\text { Latency prolonged by } \geq \mathbf{4 8} \mathbf{h r}^{\mathbf{b}} \\
\text { No tocolysis }\end{array}$ & $(\mathrm{n}=474)^{\mathrm{d}}$ & $(\mathrm{n}=494)^{\mathrm{d}}$ \\
Tocolysis & $\mathrm{Ref}$ & $\operatorname{Ref}$ \\
& $0.97(0.88-1.07)$ & $1.06(0.97-1.14)$ \\
$\begin{array}{l}\text { Histological chorioamnionitis or } \\
\text { funisitis }\end{array}$ & $(\mathrm{n}=289)^{\mathrm{e}}$ & $(\mathrm{n}=297)^{\mathrm{e}}$ \\
$\begin{array}{l}\text { No tocolysis } \\
\text { Tocolysis }\end{array}$ & $\mathrm{Ref}$ & \\
\hline & $1.06(0.92-1.23)$ & $\mathrm{Ref}$ \\
\hline
\end{tabular}

${ }^{a}$ Covariates used to estimate the propensity score: type of maternity unit, country of mother's birth, maternal age, gestational age at PPROM, PPROM before hospitalization, presence of contractions at admission, in utero transfer, antenatal steroids, antibiotics, fetal gender, presentation, birth weight $<3^{\text {rd }}$ percentile of the normalized z-score.

b Covariates used to estimate the propensity score: type of maternity unit, maternal age, gestational age at PPROM, PPROM before hospitalization, presence of contractions at admission, in utero transfer, antenatal steroids, antibiotics, fetal gender, presentation, birth weight $<3^{\text {rd }}$ percentile of the normalized z-score.

c Covariates used to estimate the propensity score: type of maternity unit, maternal age, gestational age at PPROM, PPROM before hospitalization, presence of contractions at admission, in utero transfer, antenatal steroids, antibiotics, presentation.

${ }^{\mathrm{d}}$ Obtained after multiple imputation.

${ }^{\mathrm{e}}$ For performed placental examination. 
Table A.3: Association between tocolysis administration after PPROM and survival without severe morbidity, latency prolonged by $\geq 48 \mathrm{hr}$ and histological chorioamnionitis in women admitted directly after PPROM, with and without contractions

\begin{tabular}{|c|c|c|}
\hline Outcome & $\begin{array}{l}\text { With uterine } \\
\text { contractions at } \\
\text { admission }\end{array}$ & $\begin{array}{l}\text { Without uterine } \\
\text { contractions at } \\
\text { admission }\end{array}$ \\
\hline & OR $(95 \% \mathrm{CI})$ & OR $(95 \% \mathrm{CI})$ \\
\hline $\begin{array}{l}\text { Survival without severe } \\
\text { morbidity }^{\mathrm{a}}\end{array}$ & $(\mathrm{n}=115)^{\mathrm{d}}$ & $(\mathrm{n}=135)^{\mathrm{d}}$ \\
\hline No tocolysis & Ref & Ref \\
\hline Tocolysis & $1.10(0.95-1.27)$ & $1.08(0.96-1.22)$ \\
\hline Latency prolonged by $\geq 48 \mathrm{hr}^{b}$ & $(\mathrm{n}=115)^{\mathrm{d}}$ & $(\mathrm{n}=135)^{\mathrm{d}}$ \\
\hline No tocolysis & Ref & Ref \\
\hline Tocolysis & $1.15(0.97-1.37)$ & $1.04(0.92-1.17)$ \\
\hline $\begin{array}{l}\text { Histological chorioamnionitis or } \\
\text { funisitis }^{c}\end{array}$ & $(\mathrm{n}=67)^{\mathrm{e}}$ & $(\mathrm{n}=79)^{\mathrm{e}}$ \\
\hline No tocolysis & Ref & Ref \\
\hline Tocolysis & $1.00(0.76-1.30)$ & $1.07(0.88-1.30)$ \\
\hline
\end{tabular}

a Covariates used to estimate the propensity score: type of maternity unit, country of mother's birth, maternal age, gestational age at PPROM, antenatal steroids, antibiotics, fetal gender, presentation, birth weight $<3^{\text {rd }}$ percentile of the normalized z-score.

${ }^{\mathrm{b}}$ Covariates used to estimate the propensity score: type of maternity unit, maternal age, gestational age at PPROM, antenatal steroids, antibiotics, fetal gender, presentation, birth weight $<3^{\text {rd }}$ percentile of the normalized Z-score.

c Covariates used to estimate the propensity score: type of maternity unit, maternal age, gestational age at PPROM, antenatal steroids, antibiotics, presentation.

${ }^{\mathrm{d}}$ Obtained after multiple imputation.

${ }^{\text {e }}$ For performed placental examination. 
735 Figure legends:

736

737 Title:

738 Figure 1: Flow chart of the patients in the study

739 Description of figure 1:

740 The flow chart summarizes how the sample size of the analysis was reached.

741 Legends of figure 1:

742 WG: weeks' gestation

743 PPROM: preterm premature rupture of membranes

$744 *$ Percentages are weighted by recruitment period. 


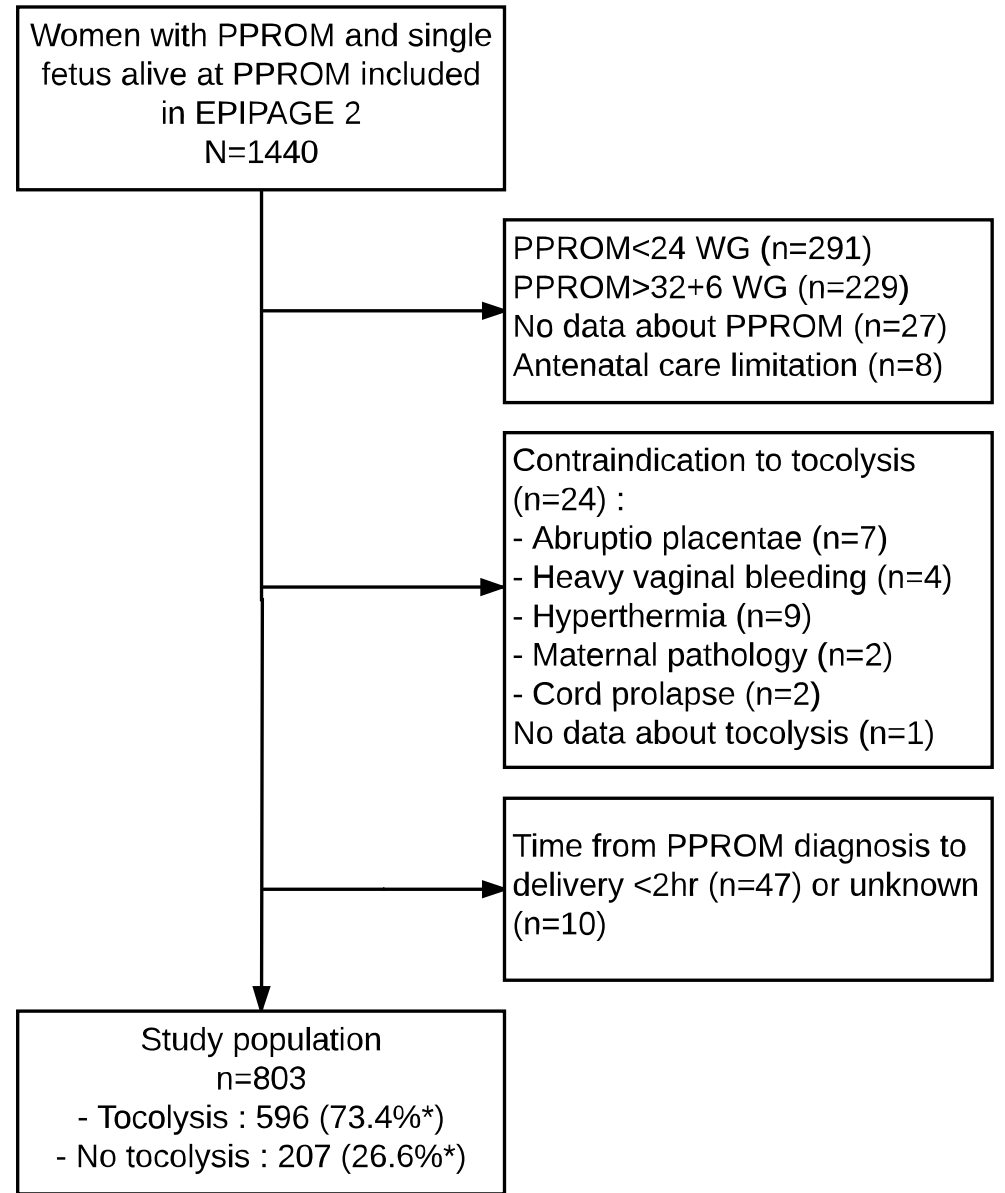

